\title{
REVIEW
}

\section{Colonization time on island settings: lessons from the Hawaiian and Canary Island floras}

\author{
C. GARCÍA-VERDUGO ${ }^{1,2, *}$, J. CAUJAPÉ-CASTELLS ${ }^{3}$ and I. SANMARTÍN ${ }^{4}$ \\ ${ }^{1}$ Departmento de Biología, Universitat de les Illes Balears, Ctra. Valldemossa km 7.5, Palma 07122, \\ Balearic Islands, Spain \\ ${ }^{2} J a r d i ́ n$ Botánico Atlántico - Universidad de Oviedo, Avda. del Jardín Botánico 2230, 33203 Gijón / \\ Xixón, Spain \\ ${ }^{3}$ Departamento de Biodiversidad Molecular y Banco de ADN, Jardín Botánico Canario 'Viera y Clavijo'- \\ Unidad Asociada CSIC, Cabildo de Gran Canaria, Camino del Palmeral 15, 35017 Las Palmas de Gran \\ Canaria, Spain \\ ${ }^{4}$ Real Jardín Botánico (RJB), CSIC, Plaza Murillo 2, 28014 Madrid, Spain
}

Received 30 March 2019; revised 20 June 2019; accepted for publication 10 July 2019

\begin{abstract}
Molecular dating offers a tool for inferring the time of divergence between two lineages. In this study, we discuss how dated molecular reconstructions are informative of two different, albeit often intermingled, time estimates with regard to a fundamental process in island biogeography: the time of island colonization (TIC). We illustrate how stem age estimates provide information on the divergence between the extant island lineage and their closest relatives (i.e. the onset of lineage differentiation). Such estimates, however, are typically poor TIC predictors, as they are strongly affected by spatial and temporal uncertainty, particularly in cases of deep stem ages. Crown ages of endemic island lineages, in contrast, provide information on the temporal onset of island in situ diversification, and may represent a better proxy for TIC when the associated uncertainty is taken into account. Thus, the geographic and temporal distance separating the island and mainland lineages in phylogenetic/phylogeographic reconstructions are key factors for determining the reliability of these two estimates as proxies of TIC. We show how divergence times can be used to investigate the biogeographic patterns of two well-studied oceanic archipelagos: Hawaii and the Canary Islands. A compilation of molecular age estimates for nearly one-third of the endemic plant lineages in each archipelago reveals that Canarian plant lineages exhibit significantly younger mean crown ages $(2.1 \pm 2.4 \mathrm{Myr})$ than Hawaiian lineages $(3.5 \pm 2.9 \mathrm{Myr})$, despite island substrates being much older in the Canarian archipelago. We postulate that this pattern suggests: (1) a more important role of submerged islands during plant colonization in Hawaii, and (2) higher taxon turnover in the Canaries, mediated by relatively young (Mediterranean) lineages, and probably facilitated by the combination of the high incidence of extinction for the last $5 \mathrm{Myr}$ and the close proximity of mainland source areas as compared to Hawaii.
\end{abstract}

KEYWORDS: crown age - extinction - island biogeography -island colonization -lineage diversificationmolecular dating- stem age - temporal uncertainty.

\section{INTRODUCTION}

One of the most important challenges in evolutionary biology is to assign a reliable estimate to the tempo of

*Corresponding author. E-mail: carlosgarciaverdugo@gmail.com lineage diversification. Our inferences on the temporal scale of macroevolutionary processes largely rely on the fossil record (Darwin, 1859; Sunding, 1979; Silvestro et al., 2016). There are, however, particular geological areas and organisms for which fossil information is very scarce or completely absent. This is often the case of 
oceanic island plants: soft plant tissues rarely fossilize on volcanic substrates, and the preservation of alternative paleobotanical records (e.g. leaf imprints, pollen) is also limited or subject to different interpretations with regard to taxonomic identification (see Woodcock \& Kalodimos, 2005; Góis-Marques et al., 2019). More recently, the development of molecular approaches has offered a useful tool for biogeographic dating of plant groups lacking fossils, thanks to the application of alternative sources for calibration (Forest, 2009; Ho et al., 2015). Thus, molecular-based methods, commonly focusing on Bayesian inference of lineage divergence times, have been routinely implemented in numerous biogeographic studies conducted over the last decade (Fig. S1).

There is abundant literature on the limitations inherent to molecular dating approaches, most notably those derived from poor taxonomic sampling or the application of unrealistic calibration approaches (e.g. Linder, Hardy \& Rutschmann, 2005; Forest, 2009; Heads, 2011; Ho et al., 2015; Schenk, 2016). Beyond such limitations, the aim of this study is to conceptualize which information obtained from dating analyses can be more informative of one key topic in island biogeography: the inference of the time of island colonization (TIC).

Island systems have traditionally served as 'natural laboratories of evolution' (García-Verdugo \& Fay, 2014), but framing the temporal setting of colonization is a fundamental requisite to refine our understanding of evolutionary processes such as trait adaptation (Talavera, Arista \& Ortiz, 2012; Monroy \& García-Verdugo, 2019), species formation (Grover et al., 2017; Pillon \& Buerki, 2017) and community assembly (Kitson et al., 2018). Bearing in mind our assessment of how divergence times can be informative on TIC, we reviewed published molecular dating estimates for island lineages endemic to two of the most well-studied island systems in the world: the Atlantic Canary Islands and the Pacific archipelago of Hawaii. Specifically, we were interested in exploring if the published data support classical biogeographic predictions, such as those linking island ages or the past availability of currently submerged islands with temporal windows for lineage colonization (Price \& Clague, 2002; Heads, 2011; Pillon \& Buerki, 2017).

The Canarian and Hawaiian archipelagos encompass a number of biotic and geologic features that provide a useful scenario for understanding the temporal dimension of island colonization under contrasting biogeographic backgrounds. First, they both harbour a high number of endemic plant lineages, thereby offering an excellent sample size of independent biological replicates for the study of TIC. Second, taxonomic and molecular studies have been particularly prolific in these two archipelagos, thus allowing a reasonably accurate delimitation of lineages within their endemic spermatophyte flora (reviewed in Baldwin \& Wagner, 2010; García-Verdugo et al., 2014; Price \& Wagner, 2018; García-Verdugo et al., 2019a). Third, geological age estimates for the main islands present contrasting temporal intervals for terrestrial colonization in the two archipelagos. Thus, the Canary Islands are composed of eight volcanic islands with substrates ranging from c. 20 to less than $1 \mathrm{Myr}$, whereas the archipelago of Hawaii also consists of eight high islands, but all age estimates indicate that they emerged from the ocean floor in the last $5 \mathrm{Myr}$ (Carson \& Clague, 1995; van den Bogaard, 2013). On the other hand, some studies have expanded both temporal backgrounds over several million years by hypothesizing the role of seamounts as former stepping stones that predated the formation of the modern islands and in part may have coexisted with them (for detailed reconstructions see Price \& Clague, 2002 and Fernández-Palacios et al., 2011). In this context, an updated revision of the molecular age estimates for endemic lineages in each archipelago may help us investigate if current estimates of TIC are consistent with the idea of seamounts as past stepping stones for present-day island lineages.

\section{STEM AND CROWN AGES OF ISLAND LINEAGES AS PROXIES FOR COLONIZATION TIME}

In essence, all attempts to assign a temporal framework to the process of island colonization rely on the amount of molecular divergence detected for the island plant lineages of interest (composed of one species or a monophyletic set of endemic species) at different phylogenetic depths. For instance, when hypothesizing the temporal origin of extant island endemics, some phylogenetically oriented studies have focused on the divergence time estimate obtained for the split between the island lineage and its closest relative from the mainland or from another island system (see examples in Keeley \& Funk, 2011; Spalik et al., 2014; Kondraskov et al., 2015; Grover et al., 2017). Such an estimate is the 'stem age' of the island lineage, but it is important to highlight that this date represents the time at which divergence between mainland and island lineages may have started. Consequently, it does not necessarily represent an accurate indicator of island residence time because stem ages are inherently associated with strong uncertainty, both temporal and spatial (Fig. 1).

One of the properties of stem-node dates that detracts from their value as proxies of TIC is that they are prone to be severely affected by the underrepresentation of putative sister taxa or populations, either due to limited sampling effort or extinction (i.e. sampling bias; Mairal et al., 2015a; Pillon \& Buerki, 2017). Failure to account for these unobserved (extinct or 

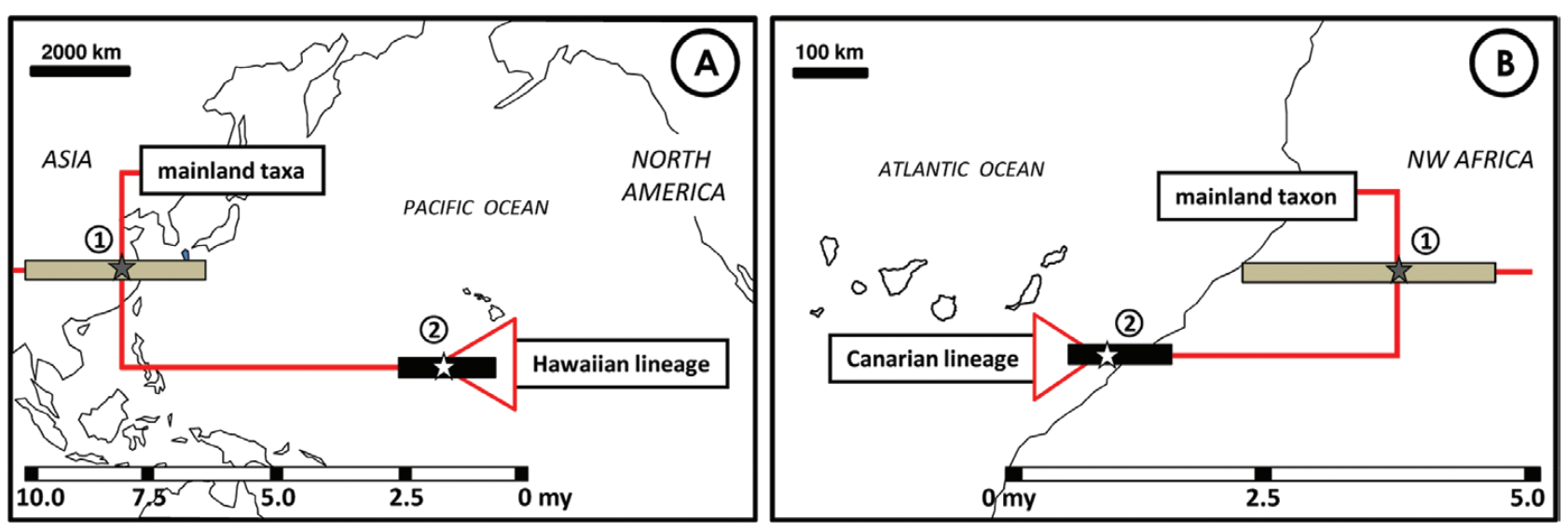

Figure 1. Temporal and spatial uncertainty for inferences of island colonization based on stem and crown-ages. A, In Hawaiian Lysimachia (data from Yan et al., 2018), the stem age estimate (8.0 Myr, 95\% HPD =6.8-10.3) suggests an old split between a mainland East Asian clade and the island lineage. The crown age estimate (1.7 Myr, 95\% HPD = 0.9-2.6) indicates that Hawaiian in situ diversification started much later, with a c. 5 Myr gap between stem and crown ages, which suggests that island colonization was considerably more recent than the island-mainland lineage split. The large geographical gap between the Hawaiian endemic and its sister lineage in East Asia $(c .7000 \mathrm{~km})$, introduces additional uncertainty on the route of island colonization. Together, these two sources of uncertainty (temporal and spatial) suggest that the crown age might be a more reliable estimate for the time of first island colonization. B, In contrast, for the Canarian Kleinia neriifolia (data from García-Verdugo et al., 2019b), the temporal gap between the stem-age (3.3 Myr, 95\% HPD = 2.3-4.2) and crown age (1.4 Myr, 95\% HPD = 0.9-1.9) estimates is smaller $(<2 \mathrm{Myr})$, which together with the geographic proximity of the inferred sister taxon, strongly suggests that island colonization was recent and probably stemmed from a NW African ancestor. Grey and black bars represent credible intervals extracted from the references for stem and crown time estimates, respectively (mean absolute ages marked with a star).

unsampled) taxa or that are most closely related to the extant island lineages virtually removes nodes from our molecular timetrees, thereby resulting in an overestimation of the divergence time between the island lineage and its (original) closest relative (Fig. 2A). Indeed, phylogenetic analyses of insular lineages whose extant closest relatives occur in geographically distant areas typically recover long branches that diverge at deep stem nodes, which has been interpreted as high uncertainty caused by extinction before the TIC (e.g. Spalik et al., 2014; Mairal et al., 2015a).

Another source of uncertainty when using stem ages as proxies for TIC is spatial: by dating these nodes, we can place the split between island and mainland counterparts within a time period, but it may not be possible to identify the area where such a split took place. This limitation is particularly important in cases of old inferred stem ages or when the island endemics are geographically distant from their inferred mainland relatives (Baldwin \& Wagner, 2010; Keeley \& Funk, 2011; Mairal et al. 2015a). Thus, deep temporal and spatial phylogenetic splits between mainland and island lineages (Fig. 1A) often translate into unclear biogeographic patterns prior to the colonization of the island, since the stem age and geographic location of the extant sister group in our reconstruction do not provide reliable information on the colonization pathway followed by the ancestor(s) of the extant island lineage.

Alternatively, studies with sampling focused on island taxa and populations give us insights on the tempo of in situ diversification, here defined as 'marked molecular divergence of the island endemic lineage, regardless of whether this pattern is recognized or not in the form of different taxonomic units'. For instance, phylogeographic studies based on robust sampling schemes show that single-species endemic lineages with multi-island distributions are typically composed of different sublineages (Dlugosch \& Parker, 2007; Mairal et al., 2015b; García-Verdugo et al., 2019b), with the 'crown age' representing the onset of the divergence from the most recent common ancestor of all extant island populations (Pokorny et al., 2015). The same interpretation applies to island endemic lineages comprising several taxonomic species that originated from a single colonization event (i.e. 'island radiations', Landis, Freyman \& Baldwin, 2018; Yan et al., 2018). In these cases, island colonization is expected to have been rapidly followed by diversification within the island setting (Kim et al., 2008). Such a pattern of diversification is often triggered by inter-island dispersal, but it may also occur within single islands over short time intervals (Garot et al., 2019; Saro et al., 2019). When all extant populations/taxa are island 

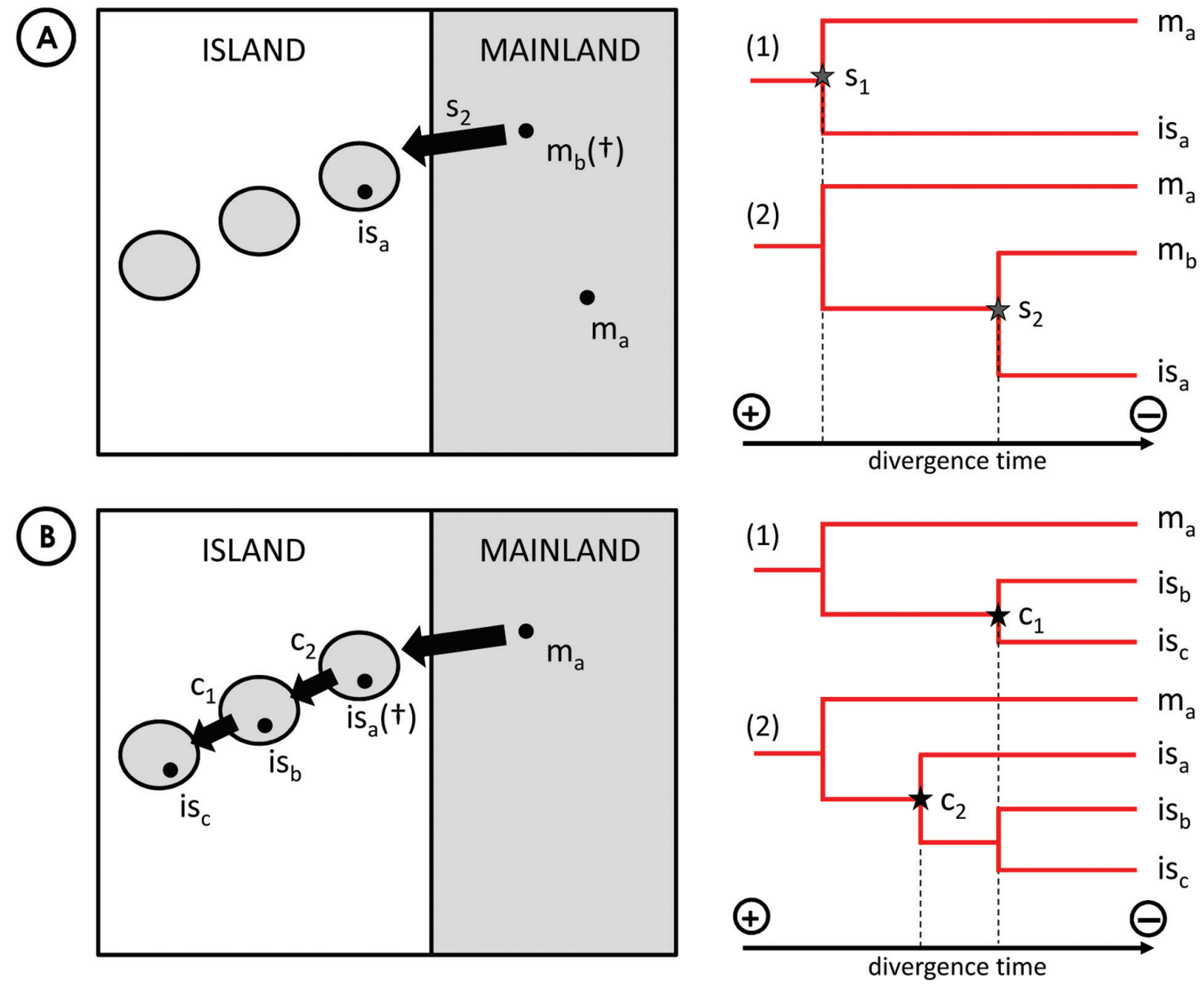

Figure 2. Impact of incomplete taxon sampling on inferences of island colonization time based on crown-age and stemage estimates. For each scenario, inferences on divergence times under incomplete (case 1) and complete (case 2) taxon/ population sampling are represented. Island (is) and mainland ( $\mathrm{m}$ ) taxa/populations are represented by dots, dispersal events are indicated with arrows and non sampled taxa/populations (including extinct ones) with a cross. In scenario A, the sister taxon of the island lineage is extinct or is not sampled (case 1), so using the age estimate of the stem node (s) overestimates the island colonization time compared with the actual estimate obtained with complete taxon sampling (case 2). For scenario B, the first diversification event within the island/archipelago is lost in the molecular reconstruction via extinction or incomplete taxon sampling (case 1), so using the age estimate of the crown node (c) underestimates the colonization time compared with the actual estimate (case 2).

endemics, it is generally accepted that crown ages may represent a reasonable proxy for TIC (Fig. 1B) (Kim et al., 2008; Landis et al., 2018).

Some sources of uncertainty, however, may also affect crown ages. For instance, if extinction pruned signatures of initial island diversification (i.e. the oldest island populations/taxa went extinct), our estimates of the onset of colonization from mean crown ages would be younger than it actually was (Fig. 2B) (see examples of Canarian lineages potentially affected by extinction in Sanmartín, van der Mark \& Ronquist, 2008, and García-Verdugo et al., 2019a). Another confounding factor for accurate inference of colonization times from crown ages may be related to the demography of the colonizers; if the founder island population does not accumulate new genetic variation for a large number of generations, the TIC would be underestimated. A growing body of evidence, however, suggests that population expansion and differentiation are often achieved following initial island colonization in a short time span, particularly if islands are large (Stuessy et al., 2014; Alsos et al., 2015; Saro et al., 2015; Fulgione et al., 2018).

Despite these caveats on the estimation of divergence times, many studies do not clearly differentiate between stem and crown ages when assessing TIC estimates obtained from molecular dating (e.g. Dlugosch \& Parker, 2007; Heads, 2011; Keeley \& Funk, 2011). In 
principle, the most logical approach would be to assign the likelihood of an event of island colonization within the time period between the mean age estimates of the stem (the onset of mainland-island split) and crown (the onset of in situ diversification) nodes (Fig. 2). Following this reasoning, the larger the temporal gap between these two estimates, the higher the uncertainty is for TIC inference (e.g. Fig. 1A). As discussed above, each of these estimates is inherently associated with sources of error derived from potential sampling bias (plus other uncertainties associated with methodological approaches such as the assumption of the molecular clock or different mutation rates across the genome), but we can generally assume that: (1) stem ages are subject to higher uncertainty, and (2) crown ages are closer estimates of the actual TIC in most cases.

The second assumption holds particularly true if the island lineages are related to geographically distant sister taxa (Fig. 1A), and the sampling of distribution areas in the islands has been extensive (which reduces sampling bias; Fig. 1B). The comparison of independent phylogenetic studies dealing with the same island lineage supports this notion: while stem ages often indicate long time spans of divergence that barely overlap among studies, crown ages can provide more congruent and narrower temporal scenarios of island colonization (see comparisons in Fig. S2). Thus, we may conclude that stem ages are useful indicators of lineage age in the sense that they give us insight into the onset of differentiation, but they are of limited value for framing the processes that occurred upon arrival in presently emerged islands. On the other hand, absolute crown ages are not free of bias, possibly providing underestimates in cases of widespread extinction (García-Verdugo et al., 2019a). Recently, Bayesian methods have been developed that allow the integration of this uncertainty in biogeographic inferences, e.g. through the use of appropriate confidence intervals (Landis et al., 2018).

\section{WHAT DO AVAILABLE AGE ESTIMATES TELL US IN TWO OCEANIC ARCHIPELAGOS WITH CONTRASTING BIOGEOGRAPHIC BACKGROUNDS?}

Keeping in mind the limitations associated with age estimates mentioned above, we compiled a dataset for all molecular-derived divergence times of Canarian and Hawaiian plant lineages published to date. Along with bibliographic searches, the recent reviews by Price \& Wagner (2018) and García-Verdugo et al. (2019a) were used to extract references and data of potential interest for the present study. In relation to the number of lineages reported in these two studies, our dataset of age estimates represented 91 Canarian cases and 52 Hawaiian cases (39 and 31\%, respectively) of the endemic lineages recognized to date in each archipelago (Tables S1, S2). For some lineages, however, data were only available for one of the two estimates (see sample sizes below).Considering this dataset, mean stem ages of Hawaiian lineages $(N=46)$ were found to be significantly larger than those obtained for Canarian lineages $(N=89)$ ( $t$-test of log-transformed values $=3.14, P=0.002$ ). Moreover, approximately $50 \%$ of the stem ages of Hawaiian lineages predated the volcanic origin of the high islands (Fig. 3, Table S2). This result agrees with the idea of Hawaiian plant lineages being the outcome of complex colonization routes followed by ancestors from disparate, distant regions (Baldwin \& Wagner, 2010; Price \& Wagner, 2018), and underscores the role of submerged seamounts and atolls in the colonization of the modern islands. In contrast, none of the stem ages for Canarian lineages predated the volcanic origin of the present islands. In each archipelago, a few lineages clearly deviated from the time interval that encompassed the stem ages of all other island lineages, but these were limited to cases with geographically distant sister taxa (Neochamaelea, Hillebrandia, Hesperomannia) or premier examples of extensive island radiation (Crambe, Hawaiian lobelioids, Zanthoxylum).

Crown ages were also significantly older for Hawaiian $(N=36)$ than for Canarian $(N=62)$ lineages ( $t$-test of log-transformed values $=3.19, P=0.002$ ). The crown age predated the origin of the islands in four Hawaiian lineages (Fig. 3, Table S2), whereas in the Canary Islands this pattern was not detected for any lineage (Fig. 3, Table S1). Recurrent immigration from nearby mainland areas or from other islands may obscure older events of colonization within Canarian lineages (Herben, Suda \& Munclinger, 2005; CaujapéCastells et al., 2017), thus potentially accounting for such young crown ages. While this possibility may be less plausible in island plant groups where monophyly is strongly supported (Silvertown, Francisco-Ortega \& Carine, 2005), multiple events of immigration (i.e. lineages) have been detected within recent island colonizing species (García-Verdugo et al., 2009; Valtueña et al., 2016; García-Verdugo et al., 2019b).

The information provided by these estimates broadly depicts a similar temporal framework for island plant colonization and diversification in both archipelagos, placing these processes within the Plio-Pleistocene period (last $5 \mathrm{Myr}$ ). Even after accounting for uncertainty in age estimates (using the confidence intervals reported for divergence times in the original studies), the pattern holds true: all but four cases in each archipelago showed crown ages (s.l.) that fell within the Plio-Pleistocene (Fig. S3). This result is consistent with early findings for the Hawaiian biota (Price \& Clague, 2002), and supports the pattern detected in the Canarian laurel forest taxa 


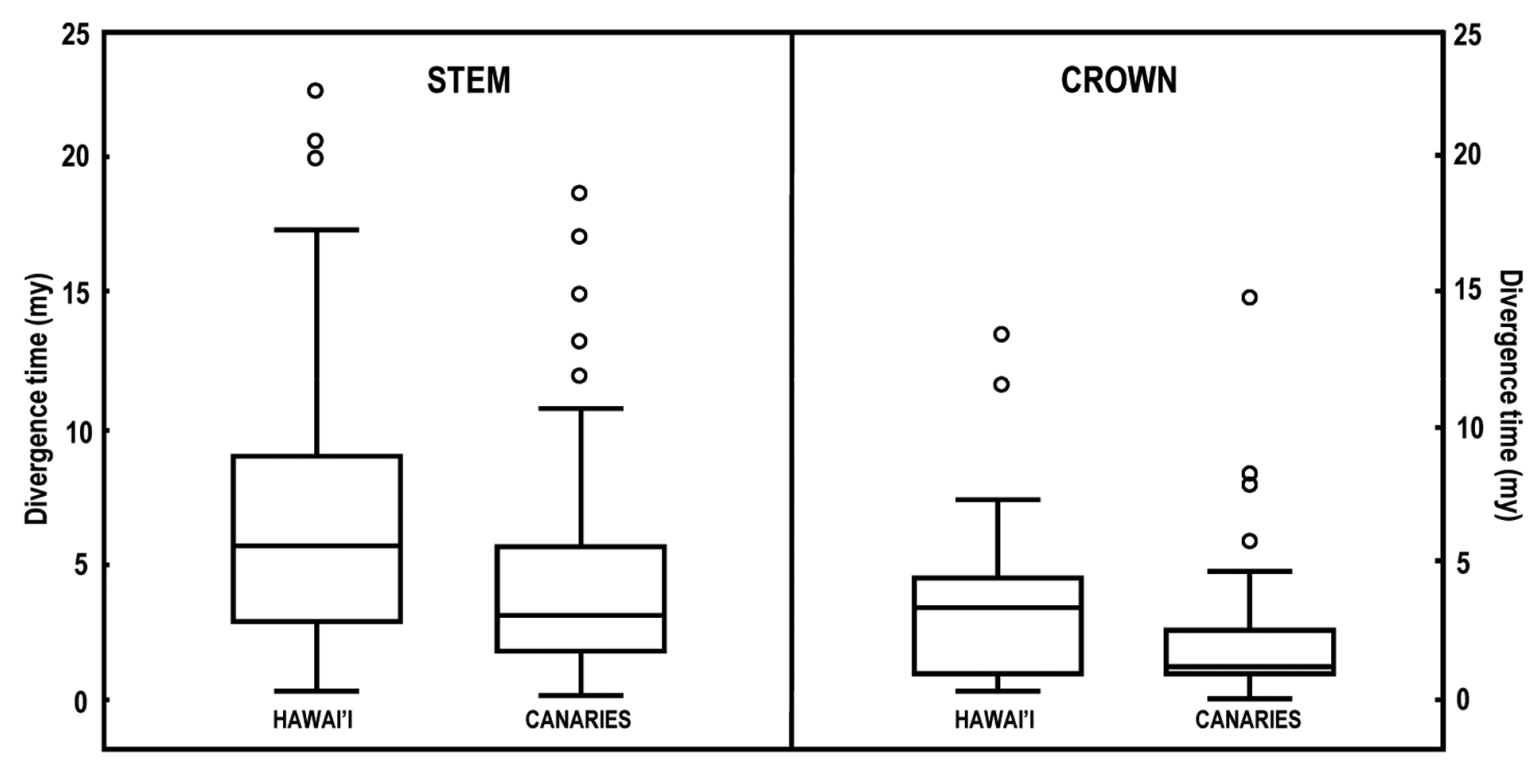

Figure 3. Box plot of mean stem age $\left(N_{\text {Hawaii }}=46 ; N_{\text {Canaries }}=89\right)$ and crown age $\left(N_{\text {Hawaii }}=36 ; N_{\text {Canaries }}=62\right)$ estimates obtained from the literature for Hawaiian and Canarian endemic plant lineages. Note: one outlier stem age of a Hawaiian lineage (Hillebrandia sandwicensis) is off-scale and not represented in the graph.

(Kondraskov et al., 2015). Notably, our analysis reveals a few island lineages - representing flagship examples of island radiations (i.e. Sonchus, Crambe, Hawaiian lobelioids, Melicope) - that do not fit this temporal framework but suggest older colonization times, which date back to the Miocene. It might be that divergence time estimates in these groups have been biased (e.g. by incorrect assumptions on substitution rates or inappropriate calibrations; Kay, Whittall \& Hodges, 2006; Heads, 2011) or that they actually represent pre-Pliocene events of insular colonization. However, the available information suggests that lineages that diversified more than $5 \mathrm{Myr}$ ago are rare on the modern islands.

According to our review of divergence time estimates (both stem and crown ages), there is little support for the hypothesis that currently submerged volcanic islands acted as dispersal corridors for extant Canarian plant lineages. The emerged part of the islands closest to the continent was already exposed during the Miocene, and the distribution and age estimates for the seamounts suggest that opportunities for island colonization could have been continuous for as long as 60 Myr (Fernández-Palacios et al., 2011). In contrast, the relatively young estimates of the colonization and initial diversification times reported in the literature coincide with the intensification of the drought season in the western Mediterranean Basin during the midPliocene (Jiménez-Moreno, Fauquette \& Suc, 2010). Such a progressive aridification of mainland source areas may in turn explain the abundance of xerophytic Mediterranean elements in the Canarian archipelago already noted by early biogeographers (Sunding,
1979). But how could these new elements successfully colonize a presumed hot-spot of Tertiary diversity? Extinction of early resident Canarian taxa, coupled with range contraction of humid habitats from the Pliocene onwards, may be a plausible answer.

Price \& Wagner (2018) estimated that the nearly 950 species endemic to Hawaii were the result of only 169 colonization events, while the $c .600$ Canarian endemics have been inferred as originating from c. 230 colonization events (García-Verdugo et al., 2019a). Considering the similar temporal framework of colonization depicted above for both archipelagos, we hypothesize that the small number of Canarian endemics as compared to Hawaii may stem (in addition to ecological factors) from the stronger impact of extinction on the Canaries since the Pliocene. Abrupt environmental shifts might have prompted extinction of former Tertiary elements and taxon turnover by Mediterranean mainland lineages. Indeed, many Canarian endemic lineages with sister species occurring in neighbouring areas of NW Africa (e.g. Asteriscus, Euphorbia, Kleinia, Periploca; reviewed in Carine et al., 2004; Pokorny et al., 2015; García-Verdugo et al.,2019b) support the idea that lowland habitats in the archipelago may have acted as ecological filters favouring the establishment of immigrants preadapted to xeric conditions. High immigration from continental areas displaying Mediterranean-like habitats was probably facilitated by the physical characteristics of the Canaries throughout the Plio-Pleistocene: smaller geographic distance from mainland areas than today, and significant contraction of humid habitats available for hygrophilous taxa (Fernández-Palacios et al., 2016). 


\section{CONCLUSIONS}

Molecular dating can be a useful tool for providing a temporal framework in island evolutionary studies. Yet, divergence time estimates are intrinsically associated with several sources of uncertainty, and researchers should critically evaluate to what extent their study system allows for strong inferences on the temporal dimension of island colonization (for example, when the closest relative occurs in a geographically distant area). We postulate that crown ages are generally a much closer predictor of residence time than stem ages, but the former can also be affected by sampling bias. Integration of this uncertainty, e.g. working with time intervals instead of mean ages, might help improve inference of the temporal framework of island colonization in biogeographic studies.

Finally, given that the magnitude and the sources of bias in age estimates are likely similar in Hawaii and the Canaries, our analysis suggests that the floras of these two oceanic archipelagos with contrasting biogeographic characteristics (geological age, distance to source areas) were assembled essentially during the Plio-Pleistocene period, which is at odds with hypotheses that link island age with lineage colonization in the Canaries. However, many plant lineages remain to be analysed, and new analyses will probably refine some of the patterns described in published studies. Only a more complete representation of lineages will help us disentangle the general spatio-temporal patterns that drove the assemblage of these island floras.

\section{ACKNOWLEDGEMENTS}

We really appreciate the stimulating feedback and the useful data provided by several colleagues interested in the topic of this paper: P. Bruyns, M. Gruenstaeudl, M. Mairal, G. Nieto Feliner, J. Patiño, A. Reyes Betancort and K. Spalik. Special thanks to J.M. Fernández-Palacios for critically reading the draft and providing ideas to broaden the discussion. We also acknowledge the constructive comments and the edits suggested by three anonymous reviewers. I.S. was funded by the Spanish Government and the European Regional Development Fund (MNECO/ FEDER, grant CGL2015-67849-P), and C.G.-V. was supported by a "Vicenç Mut" postdoctoral fellowship (Govern de les Illes Balears).

\section{REFERENCES}

Alsos IG, Ehrich D, Eidesen PB, Solstad H, Westergaard KB, Schönswetter P, Tribsch A, Birkeland S, Elven R, Brochmann C. 2015. Long-distance plant dispersal to North Atlantic islands: colonization routes and founder effect. AoB Plants 7: plv036.
Baldwin BG, Wagner WL. 2010. Hawaiian angiosperm radiations of North American origin. Annals of Botany 105: 849-879.

van den Bogaard P. 2013. The origin of the Canary Island seamount province - new ages of old seamounts. Scientific Reports 3: 1-7.

Carine MA, Russell SJ, Santos-Guerra A, FranciscoOrtega J. 2004. Relationships of the Macaronesian and Mediterranean floras: molecular evidence for multiple colonizations into Macaronesia and back-colonization of the continent in Convolvulus (Convolvulaceae). American Journal of Botany 91: 1070-1085.

Carson HL, Clague DA. 1995. Geology and biogeography of the Hawaiian Islands. In: Wagner WL, Funk VA, eds. Hawaiian biogeography: evolution on a hotspot archipelago. Washington: Smithsonian Institution Press, 14-29.

Caujapé-Castells J, García-Verdugo C, MarreroRodríguez A, Fernández-Palacios JM, Crawford DJ, Mort ME. 2017. Island ontogenies, syngameons, and the origins and evolution of genetic diversity in the Canarian endemic flora. Perspectives in Plant Ecology, Evolution and Systematics 27: 9-22.

Darwin C. 1859. On the origin of species. London: John Murray. Dlugosch KM, Parker IM. 2007. Molecular and quantitative trait variation across the native range of the invasive species Hypericum canariense: evidence for ancient patterns of colonization via pre-adaptation? Molecular Ecology 16: 4269-4283.

Fernández-Palacios JM, Nascimento de L, Otto $R$, Delgado JD, García-del-Rey E, Arévalo JR, Whittaker RJ. 2011. A reconstruction of PalaeoMacaronesia, with particular reference to the long-term biogeography of the Atlantic island laurel forests. Journal of Biogeography 38: 226-246.

Fernández-Palacios JM, Rijsdijk KF, Norder SJ, Otto R, de Nascimento L, Fernández-Lugo $S$, Tjørve E, Whittaker RJ. 2016. Towards a glacial-sensitive model of island biogeography. Global Ecology and Biogeography 25: 817-830.

Forest F. 2009. Calibrating the tree of life: fossils, molecules and evolutionary timescales. Annals of Botany 104: 789-794.

Fulgione A, Koornneef M, Roux F, Hermisson J, Hancock AM. 2018. Madeiran Arabidopsis thaliana reveals ancient long-range colonization and clarifies demography in Eurasia. Molecular Biology and Evolution 35: 564-574.

García-Verdugo C, Baldwin BG, Fay MF, Caujapé-Castells J. 2014. Life history traits and patterns of diversification in oceanic archipelagos: a meta-analysis. Botanical Journal of the Linnean Society 174: 334-348.

García-Verdugo C, Caujapé-Castells J, Illera JC, Mairal M, Patiño J, Reyes-Betancort JA, Scholz S. 2019a. Pleistocene extinctions as drivers of biogeographical patterns on the easternmost Canary Islands. Journal of Biogeography 46: 845-859.

García-Verdugo C, Caujapé-Castells J, Mairal M, Monroy P. 2019b. How repeatable is microevolution on islands? Patterns of dispersal and colonization-related plant 
traits in a phylogeographical context. Annals of Botany 123: $557-568$.

García-Verdugo C, Fay MF. 2014. Ecology and evolution on oceanic islands: broadening the botanical perspective. Botanical Journal of the Linnean Society 174: 271-275.

García-Verdugo C, Fay MF, Granado-Yela C, DE Casas RR, Balaguer L, Besnard G, Vargas P. 2009. Genetic diversity and differentiation processes in the ploidy series of Olea europaea L.: a multiscale approach from subspecies to insular populations. Molecular Ecology 18: 454-467.

Garot E, Joët T, Combes M-C, Lashermes P. 2019. Genetic diversity and population divergences of an indigenous tree (Coffea mauritiana) in Reunion Island: role of climatic and geographical factors. Heredity DOI: 10.1038/ s41437-018-0168-9

Góis-Marques CA, de Nascimento L, Menezes de Sequeira M, Fernández- Palacios JM, Madeira J. 2019. The Quaternary plant fossil record from the volcanic Azores archipelago (Portugal, north Atlantic Ocean): a review. Historical Biology DOI: 10.1080/08912963.2018.1444761

Grover CE, Arick MA 2 ${ }^{\text {nd }}$, Conover JL, Thrash A, Hu G, Sanders WS, Hsu CY, Naqvi RZ, Farooq M, Li X, Gong L, Mudge J, Ramaraj T, Udall JA, Peterson DG, Wendel JF. 2017. Comparative genomics of an unusual biogeographic disjunction in the cotton tribe (Gossypieae) yields insights into genome downsizing. Genome Biology and Evolution 9: 3328-3344.

Heads M. 2011. Old taxa on young islands: a critique of the use of island age to date island-endemic clades and calibrate phylogenies. Systematic Biology 60: 204-218.

Herben T, Suda J, Munclinger P. 2005. The ghost of hybridization past: niche pre-emption is not the only explanation of apparently monophyly in island endemics. Journal of Ecology 93: 572-575.

Ho SY, Tong KJ, Foster CS, Ritchie AM, Lo N, Crisp MD. 2015. Biogeographic calibrations for the molecular clock. Biology Letters 11: 20150194.

Jiménez-Moreno G, Fauquette S, Suc JP. 2010. Miocene to Pliocene vegetation reconstruction and climate estimates in the Iberian Peninsula from pollen data. Review of Palaeobotany and Palynology 162: 403-415.

Kay KM, Whittall JB, Hodges SA. 2006. A survey of nuclear ribosomal internal transcribed spacer substitution rates across angiosperms: an approximate molecular clock with life history effects. BMC Evolutionary Biology 6: 36 .

Keeley SC, Funk VA. 2011. Origin and evolution of Hawaiian endemics: new patterns revealed by molecular phylogenetic studies. In: Bramwell D, Caujapé-Castells, J, eds. The biology of island floras. Cambridge: Cambridge University Press, 57-88.

Kim SC, McGowen MR, Lubinsky P, Barber JC, Mort ME, Santos-Guerra A. 2008. Timing and tempo of early and successive adaptive radiations in Macaronesia. PLoS One 3: e2139.

Kitson JJN, Warren BH, Thébaud C, Strasberg D, Emerson BC.2018. Community assembly and diversification in a species-rich radiation of island weevils (Coleoptera: Cratopini). Journal of Biogeography 45: 2016-2026.
Kondraskov P, Schütz N, Schüßler C, de Sequeira MM, Guerra AS, Caujapé-Castells J, Jaén-Molina R, Marrero-Rodríguez Á, Koch MA, Linder P, KovarEder J, Thiv M. 2015. Biogeography of Mediterranean hotspot biodiversity: re-evaluating the 'Tertiary Relict' hypothesis of Macaronesian Laurel forests. PLoS One 10: e0132091.

Landis MJ, Freyman WA, Baldwin BG. 2018. Retracing the Hawaiian silversword radiation despite phylogenetic, biogeographic, and paleogeographic uncertainty. Evolution 72: 2343-2359.

Linder HP, Hardy CR, Rutschmann F. 2005. Taxon sampling effects in molecular clock dating: an example from the African Restionaceae. Molecular Phylogenetics and Evolution 35: 569-582.

Mairal M, Pokorny L, Aldasoro JJ, Alarcón M, Sanmartín I. 2015a. Ancient vicariance and climate-driven extinction continental-wide disjunctions in Africa: the case of the Rand Flora genus Canarina (Campanulaceae). Molecular Ecology 24: 1335-1354.

Mairal M, Sanmartín I, Aldasoro JJ, Culshaw V, Manolopoulou I, Alarcón M. 2015b. Palaeo-islands as refugia and sources of genetic diversity within volcanic archipelagos: the case of the widespread endemic Canarina canariensis (Campanulaceae). Molecular Ecology 24: 3944-3963.

Monroy P, García-Verdugo C. 2019. Testing the hypothesis of loss of defenses on islands across a wide latitudinal gradient of Periploca laevigata populations. American Journal of Botany 106: 303-312.

Pillon Y, Buerki S. 2017. How old are island endemics? Biological Journal of the Linnean Society 121: 469-474.

Pokorny L, Riina R, Mairal M, Meseguer AS, Culshaw V, Cendoya J, Serrano M, Carbajal R, Ortiz S, Heuertz M, Sanmartín I. 2015. Living on the edge: timing of Rand Flora disjunctions congruent with ongoing aridification in Africa. Frontiers in Genetics 6: 154.

Price JP, Clague DA. 2002. How old is the Hawaiian biota? Geology and phylogeny suggest recent exchange. Proceedings of the Royal Society of London B 269: 2429-2435.

Price JP, Wagner WL. 2018. Origins of the Hawaiian flora: phylogenies and biogeography reveal patterns of long-distance dispersal. Journal of Systematics and Evolution 56: 600-620.

Sanmartín I, van der Mark P, Ronquist F. 2008. Inferring dispersal: a Bayesian approach to phylogeny-based island biogeography, with special reference to the Canary Islands. Journal of Biogeography 35: 428-449.

Saro I, García-Verdugo C, González-Pérez MA, Naranjo A, Santana A. Sosa P. A. 2019. Genetic structure of the Canarian palm tree (Phoenix canariensis) at the island scale: does the 'island within islands' concept apply to species with high colonisation ability? Plant Biology 21: 101-109.

Saro I, González-Pérez MA, García-Verdugo C, Sosa PA. 2015. Patterns of genetic diversity in Phoenix canariensis, a widespread oceanic palm (species) endemic from the Canarian archipelago. Tree Genetics \& Genomes 11: 815. 
Schenk JJ. 2016. Consequences of secondary calibrations on divergence time estimates. PLoS One 11: e0148228.

Silvertown J, Francisco-Ortega J, Carine M. 2005. The monophyly of island radiations: an evaluation of niche preemption and some alternative explanations. Journal of Ecology 93: 635-657.

Silvestro D, Zizka A, Bacon CD, Cascales-Miñana B, Salamin N, Antonelli A. 2016. Fossil biogeography: a new model to infer dispersal, extinction and sampling from palaeontological data. Philosophical Transactions of the Royal Society B, Biological Sciences 371: 20150225.

Spalik K, Banasiak Ł, Feist MA, Downie SR. 2014. Recurrent short-distance dispersal explains wide distributions of hydrophytic umbellifers (Apiaceae tribe Oenantheae). Journal of Biogeography 41: 1559-1571.

Stuessy TF, Takayama K, López-Sepúlveda $P$, Crawford DJ. 2014. Interpretation of patterns of genetic variation in endemic plant species of oceanic islands. Botanical Journal of the Linnean Society 174: 276-288.
Sunding P. 1979. Origins of the Macaronesian flora. In: Bramwell D, ed. Plants and islands. London: Academic, $13-40$.

Talavera M, Arista M, Ortiz PL. 2012. Evolution of dispersal traits in a biogeographical context: a study using the heterocarpic Rumex bucephalophorus as a model. Journal of Ecology 100: 1194-1203.

Valtueña FJ, López J, Alvarez J, Rodríguez-Riaño T, Ortega-Olivencia A. 2016. Scrophularia arguta, a widespread annual plant in the Canary Islands: a single recent colonization event or a more complex phylogeographic pattern? Ecology and Evolution 6: 4258-4273.

Woodcock D, Kalodimos N. 2005. Tree mold evidence of loulu palm (Pritchardia sp.) forest on the Kona coast, Hawaii. Pacific Science 59: 491-498.

Yan HF, Zhang CY, Anderberg AA, Hao G, Ge XJ, Wiens JJ. 2018. What explains high plant richness in East Asia? Time and diversification in the tribe Lysimachieae (Primulaceae). The New Phytologist 219: 436-448.

\section{SUPPORTING INFORMATION}

Additional Supporting Information may be found in the online version of this article at the publisher's web-site:

Figure S1. Bibliographic references over the last 19 years within the field 'island biogeography' filtered by two key words (Source: ISI Web of Knowledge).

Figure S2. Contrasting temporal scenarios based on molecular age estimates inferred by different biogeographic studies for the same island lineage. Grey stars indicate stem ages, whereas white stars with a triangle refer to crown ages and the onset of island diversification. Bars associated with each star represent $95 \%$ high posterior density (HPD) credible intervals. Note that stem ages with associated confidence intervals show long time spans of divergence that barely overlap among studies, whereas crown ages point towards a Plio-Pleistocene origin for all three island lineages.

Figure S3. Graphical representation of divergence times with confidence intervals for island lineages for which both stem and crown ages were available in the literature $\left(N_{\text {Hawaii }}=27 ; N_{\text {Canaries }}=33\right)$. Stars indicate mean absolute ages for each estimate, and bars 95\% HPD intervals. The geological age of the oldest island of each archipelago (Fuerteventura, in the Canaries; Kauai, in Hawaii) is indicated with a dashed black line.

Table S1. Data extracted from the literature for mean (95\% HPD) stem and crown age estimates for endemic Canarian lineages (including those with distributions including other Macaronesian islands). The '?' symbol indicates lack of information for that particular estimate.

Table S2. Data extracted from the literature for mean (95\% HPD) stem and crown age estimates for endemic Hawaiian lineages. The '?' symbol indicates lack of information for that particular estimate. 